\title{
VERSITA
}

DOI: 10.2478/v10299-012-0019-9

\section{The Problem and Needs of Existing Urban Multifamily Building Estates in Poland}

\author{
Adam Rybka \\ Department of Town Planning and Architecture, \\ Rzeszow University of Technology, Rzeszow, Poland \\ e-mail: akbyr@prz.edu.pl \\ Sławomir Rybka \\ Department of Environmental Protectionand Water Management \\ Boguchwala Town Municipality, Boguchwała, Poland \\ e-mail: slawomirrybka@vp.pl
}

\begin{abstract}
The present paper explains in a descriptive way the findings and derivations, concerning the various needs, solutions and priorities which are identified in existing urban building envelopes of Poland, especially in Rzeszow housing estates.
\end{abstract}

Key words: housing estates, urban building envelopes, aspects of evaluation

\section{Introduction}

Why the modernization of existing multifamily buildings, causes problems to the Polish building envelopes, need some explanation. Due to the lack of infrastructure armed terrains, Polish towns face severe lack of land for various land uses, mainly like development land. This has a direct effect on the demand and cost of land, as well as the type of building systems and planning provisions. One has to suggest in order compensating this lack. In addition to that due to the restrictions of the right of access, movement, settlement and work, all human activities, planning, economy are restricted within isolated parts of the cities, with many implications and consequences in regional and town planning, building systems, building regulations.

The derivation of the state of the art, as far as "the needs" in each town are concerned, was based on specific groups of criteria. The core issues or problems concerning the groups of criteria are explained below. 


\section{Problems - needs - solutions}

\subsection{Planning aspects}

The main planning problems are basically derived from the fact that the vast majority of developments in Poland are based nowadays on individual plots. Nowadays the development system in Polish towns was encouraging the connection of small building plots in biggest one, but this action failure. As a consequence the new building quarters in Polish towns are small, the percentage of road surfaces to other urban surfaces is quite high (25-30\%), our urban settlements are very condensed and the population densities relatively high.

Another serious planning problem seems to be the neglect of the climatic and environmental conditions. Given the constraint of the small building plots, mentioned above, the designers have limited chances to exploit the opportunities of any site's orientation, topography, local winds, and vegetation. Therefore is rather difficult to spot a few environmentally functional building envelopes. Even the limited numbers of organized developments that allow some more design freedom are usually fixed to the surrounding grid system and the norms of projects.

The major problem in big individual buildings is the land use variety and common spaces or areas that can be used by the inhabitants or other users for relaxation and social interaction. In bigger building complexes of the private sector one could face the same absence of any supporting uses and functions, mainly because the respective provisions do not allow such flexibility, but also because the main interesting partners avoid using valuable square meters for the sake of human relations quality. The only exception can be found in some big housing estates which are supported by local commercial centers. Important problems of renovation one can find in existing big, precast housing estates construct in sixties and seventies years in XX century.

\subsection{Environmental aspects}

Because there is not relevant legislation, very few buildings are studied from the environmental point of view. LCA (life cycle analyses) analyses of the new and existing buildings are completely unavailable. Day lighting is concerned some problems arise due to the number, size and type of windows. In general, Polish houses seem to have much more windows area than those needed. Ventilation problems are due to the fact that most of the housing buildings are fixed according to the existing urban systems. Also because very few buildings accommodate any simple mechanisms, like untight new windows, skylights that can partly reroute the air circulation in the building. The general energy performance, including heating and cooling, of the majority of the buildings is rather poor. This is a result of no sufficient building envelope insulations, old substandard windows detailing and finishes and ignorance of passive measures and techniques. One can find this problems in new constructed and existing buildings.

Nevertheless the increase of fuel prices in the international market during the last few years, as well as the various European Union's directives concerning CO2 emission limits, renewable energy targets and above all the ongoing establishment e. g. by the Government 
Authority of a mandatory building energy performance certificate, lead us to the conclusion that one should expect more environmentally oriented buildings in the forthcoming years.

\subsection{Architectural aspects}

Poland enjoys they climate which comprises more or less long and hot summers and cold winters. Therefore, in summer, a long period of everyday life takes or could take place, in open or semi-closed places. Nevertheless the housing units of the examining period (constructed in sixties and seventies years of XX century) do not have to show many of these spaces. It is only recently that some incentives were offered in order to support the provision of such spaces. The establishment of more incentives for the creation of more functional semi-closed spaces will improve the existing situation.

On the other hand poor aesthetics is one of the main architectural problems of Polish multi storey housing buildings. This is a much more complicated issue which can be partially handled through further clarification of aesthetic criteria and the establishment of a reliable enforcement system. Furthermore one could think of additional provisions that facilitate the adaptation of all sorts of machineries and equipments usually spread on the roofs of the buildings as well as the adoption of more incentives for promoting big organized housing complexes. Measures for eliminating unauthorized designs by non professionals and for convincing the public to trust professional designers can be also adopted.

\subsection{Structural aspects}

The critical issue in this field is the poor level of the appropriate enforcement system which would allow a reliable tough control on the quality standards of raw building materials. In addition to that another two major problems appear in this area. The first concerns the improvement of the responsibility of approving the structural analysis and design of buildings by the competent authorities whereas the second concerns the strengthen of a reliable enforcement system that will safeguard the reliable realization of the approved designs.

The most habitual problem that Poland faces in this area is the poor thermal insulation of the majority of the housing units. This has direct and severe implications on the energy consumption and the discomfort many people experience. In this case certain parts of the building envelopes, like the roofs and external openings, have to attract more of our attention than others. Besides that one could mention of course some other problems:

- The moisture problems, due to substandard plumbing installations

- Poor ventilation and the poor acoustic insulation, due to light building envelopes

Unfortunately traditional construction methods, techniques and materials have been ignored for the sake of fast development and easy profit, by the building industry, due to the absence of the necessary statutory framework that would guarantee the building quality, but also due to poor awareness of consumers' rights.

Therefore a lot can be done in this area. First of all the statutory improvement of the necessary standards concerning: thermal standards, acoustic standards, the dangerous building materials. Today not all the group of buildings have to meet certain thermal, acoustic requirements and the safe building materials. Moreover some issues concerning the need for licensing all the 
necessary construction details of the buildings. Finally, a last but not least issue, concerns the enforcement of the various permits provisions by the competent authorities.

\subsection{Cultural aspects and Social aspects}

The improvement and enhancement of the cultural, heritage and traditional aspects of our buildings and complexes can be achieved through the acknowledgment and the establishment of the respective values that are directly related to buildings, through social surveys and other analytical and systematic studies, which should be undertaken mainly by research bodies. Very important aspect is to find and to use regional details and shapes in buildings.

Today very few things of our building culture are respected and applied. One of those deals with the height of the structures. Housing building envelopes are in close relation with the earth. As a result multi storey housing buildings, have to have usually a height of 3 to 5 floors and very often more than 6 . It is believed that much more can be done in this field, and as was mentioned above, this matter is considered to be the highest priority that has to be studied on a systematic basis.

Social aspects are usually ignored because they are not directly related to primary human needs but rather to comfort and quality needs of people. On the one side designers and contractors prefer the straight-forward solutions that satisfy the main human's needs. On the other hand, most of the buyers and tenants prefer simpler and cheaper housing units, than buildings or complexes that accommodate social spaces, like closed, semi-open or open sitting or meeting places, interactive land uses. This is because social places will have an increase on the cost of the buildings or the rents. The only foreseen chance to improve the situation is by strengthening the incentives so that the adequate social spaces are excluded from the plot ratio of housing buildings, by enforcing the developers. Plus the Local Authorities to complete and manage in a satisfactory way all the public areas of housing complexes, according to the terms of their respective development permits and by allowing some mild supporting uses, like small cafes offices, clubs, to be accommodated in close relation with housing developments.

\subsection{Financial aspects}

Last but not least problem is the general financial environment, which sets a common denominator for the whole construction industry and the supply and demand market.

Given the fact the majority of the Polish families no possess their own housing unit, it is well understood from the very beginning that, the demand for housing land and housing units is quite high. Things get more complicated if one takes into account that in addition to that, the demand for land is doubling due to extra demands either from investors who decide that the Stock Exchange does not offer any more as many chances as the land market.

These aspects are somehow outside the scope of engineers and planners fields, although they are very much connected with how much people afford to pay, their preferences and choices, the banking system. It is believed that the members of the Polish Parliament and the responsible government departments, should seek a more active intervention, in order to facilitate the construction and development sector. It is important to balance the real demand 
and supply and reduce the financial and technical demand, which strengthens the investment and trade sides of land and housing units.

\section{Selected case study}

The Nowe Miasto area is the largest settlement in the city of Rzeszow with over 16,000 inhabitants. Nowe Miasto is the most classic residential blocks of flats area but moreover, there are single-family houses and serial houses there too. It is situated in the southern part of Rzeszow city. The centre of the Nowe Miasto development is located about $1.5 \mathrm{~km}$ from the Rzeszow city centre. The area of the Nowe Miasto is about $3.0 \mathrm{~km}^{2}$, which gives population density at the level of 5,300 persons per $1.0 \mathrm{~km}^{2}$. In 1977, the first building of Nowe Miasto was completed. In 1983 the development consisted of 25 buildings with 9,000 inhabitants. Next 12 blocks of flats were built during following couple of years. These 37 buildings are the core of the development. Also there were schools, shops and post office constructed there. In recent times, in the Nowe Miasto has developed a shopping district - there are hypermarkets, shopping malls there. The advantage of the district is good communication from the city center. In recent years, this has helped by built the Castle Bridge.

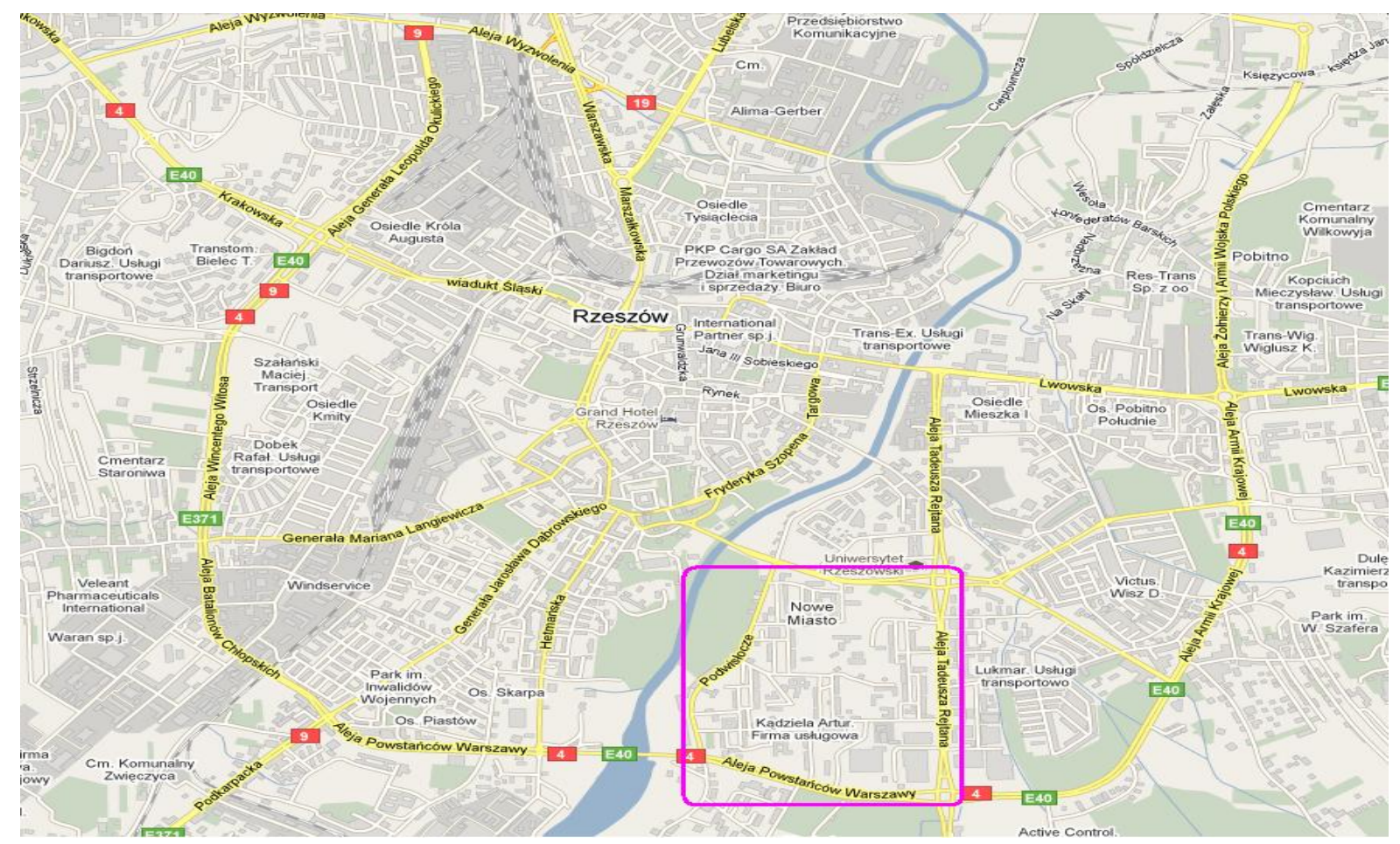

Figure 1: Rzeszow - the town map. Nowe Miasto estate

Nowe Miasto area is a typical polish housing development consisting of 11 storey high blocks of flats. These kinds of developments were realized across the country to satisfy the huge dwelling needs of the polish population. In Poland the situation improved since then, but there is still estimated at about 3 millions flats needed in Poland. Buildings followed a simple 
cubic form, for functional, economical and practical reasons. No efforts for differentiations were made during the primary construction phase. All the multi-story buildings of the estate followed the typical flat slabs concrete structure, filled with plastered walls.

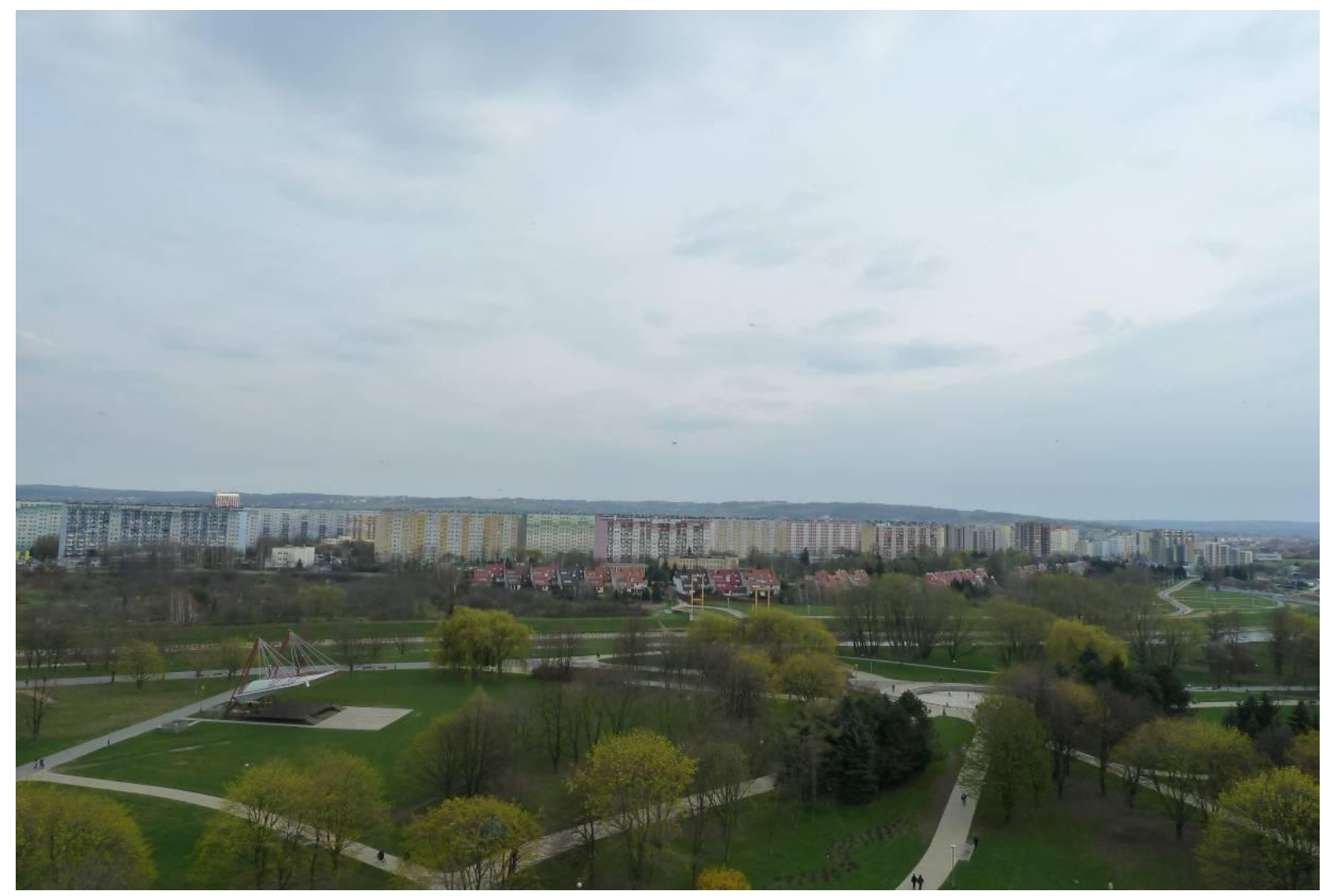

Figure 2: Rzeszow - view of the Nowe Miasto estate.

This estate faced a lot of problems like:

- energy performance problems,

- poor thermal and moisture insulation problems,

- aesthetics problems,

- structural problems.

Some people antisocial behavior was also spotted in the area. For all these reasons the Local Authorities have undertook an integrated renovation program. The main goal was to improve the living conditions of the estate. The reconstruction of the buildings was based on typical and conventional techniques and materials. Nowe Miasto refurbishment project started in mid 1990s. Nowe Miasto Housing Co-operative is the owner of all the buildings in settlement also is responsible for management of the buildings as well as whole area. It is believed that due to the renovation program applied, the various land uses incorporated in the peripheral area, and the gradual integration of the estate in the surrounding urban fabric, the area will share much better living conditions and a substantial improved environment. 
In the end 1990s, most of improvement works have been done in the district: windows and doors were also replaced in these buildings, thermo-renovation of all apartment buildings were started. All works were financed by Housing Co-operative. The money for that comes from all co-operative members who pay monthly for "refurbishment fund" Also, many new, privately owned services like: new shops, restaurants, clubs, become available. This settlement still satisfy Polish standards. Dwellings are quite functional although the particular rooms are rather small. Thanks to thermal renovation the energy consumption has been strong limited. Nowe Miasto has also good enough access to the city centre with all its services. Moreover, due to a number of bus lines operating in the area, it is easy accessible from any other district of the city. All services are available in the area, as it border on the city's biggest commercial centers.

Main problems that need to be worked out in the future are: improve the quality of natural ventilation, recuperation of natural ventilation, accessibility of the buildings, the lack of sufficient quantities of green and recreational areas, poor quality of the public spaces and shortage of parking spaces.

\section{Vulnerability analysis of piping systems}

Widely accepted, especially in the United States, by dealing with aspects of the protection of industrial buildings and high-risk critical infrastructure vulnerability analysis methodology is - SVA called Security Vulnerability Assessment. SVA analysis allows the assessment of vulnerability of individual installations of risk for terrorist attacks and other side effects, based on a risk assessment is also possible to make adequate protection and prevention. A few years ago the terrorist attacks on critical infrastructure facilities and installations venture treated as improbable. This approach has changed after the events in the USA of 11 September 2001. Given the relatively large potential adverse consequences, they should no longer be considered in the design phase, then the implementation and operation of critical infrastructure systems. SVA is a qualitative analysis, which is based on the opinion of experts in the field of safety and security. SVA is a tool used by operators of pipeline systems, including water, in decisions on security. SVA is also useful in estimating the losses and consequences of potential accidents or terrorist attacks. The use of SVA process can, in principle, it is necessary to create a so-called. -Pipeline Safety Plan (PSP called Pipeline Security Plan). PSP plan relates to protection against adverse events, organizational monitoring activities to prevent and mitigate the consequences of adverse events, such as accidents, terrorist attacks, etc. SVA is an analytical process in which an operator determines the potential risks and possible adverse events. If possible, try to determine the type and scale of the consequences that can cause these events.

Conducting the process of SVA is a key element for the construction of water supply security system.

To create the PSP for the water supply is necessary to:

- Conduct safety assessments in order to implement the best methods to reduce the risk,

- Standardization of safety,

- Carrying out control measurements to reduce the risk of danger, 
- Outlining ways of reducing the adverse effects of the accident,

- To identify potential terrorist threats and acts of sabotage,

- Monitoring the implementation of the main objectives of the security plan for water supply.

A healthy flow of information is a key factor in creating the proper safety pipeline plan. It is also important fact to remember is that the pipeline security plan must be flexible. The security plan should be based on several basic elements listed and described in further considerations. [8] The first element is to create a set of primary information, the aim is to get as much data about potential risks. Operator's task is to collect baseline information, their evaluation and analysis, which should lead to a spatial location of the risk of water supply system. The second element is the use of SVA in the initial phase of creating the security plan. The information collected in the previous phase will be used to carry out the procedures for the SVA system. SVA procedure begins with a comprehensive testing system for verifying the potential risk. Risk identification must be conducted in relation to the new locally to date types of threats, and not confined only to the known risks. Through research SVA, you can specify the area where the failure is not only the most probable, but also where a failure plagues them most threatening consequences. SVA allows to estimate the actual effects of the accident in several categories: environment, tangible property, society. After grouping these categories shall be converted into the effects of the monetary unit for better visualization and easier to compare them with each other. After locating the most endangered in the risk component of the system determines the type of proceedings which might minimize the threat. SVA is also useful in identifying components most vulnerable to terrorist attacks, and those where the occurrence of an attack is unlikely. Using the analytical results SVA developed a basic security plan that includes the most dangerous categories of risk of the system. The plan should include types of monitoring, control efforts, inspection and security measures. Data on safety system should be updated by the operator. Periodically carry out a further analysis of the SVA to help you update your security plan. These actions included new episodes of water supply, information technology, new technical devices introduced to the action SZZW. The analysis should also be subject to new external factors that may affect the security of water supply network. New information about potential risks should be used to update the security plan. The operator is obliged to collect information about the effectiveness of introduced technologies to reduce risk. Develop a security plan is a multi-and complex process. The security plan is based on the continuous process of monitoring the network status, evaluate and identify risks and implement measures aimed at elimination of the largest and most dangerous risk. Risk management is a complex process of understanding risk and taking appropriate actions to reduce risk to acceptable levels by the rationalization of costs.

\section{Conclusions}

As it can be seen the various need issues were ranked in groups as follows:

- Group 1 includes the need issues like:

energy performance,

building aesthetics, 
thermal insulation,

building management,

- Group 2 includes:

the environmental and climatic planning,

the need to cope to dead load,

the cultural, social and financial needs,

- Group 3 includes:

the need for better distribution of building volumes,

some sort of land use variety at building level,

the need for earthquake resistance,

the acoustic insulation needs.

Going a step further it should be mentioned that the most important need issues (outcome from Group 1), were classified as follows: general energy performance and thermal insulation, aesthetic issues and finally the tough financial environment.

There is no doubt that if some or all of the problems related to buildings, could be reduced, solved, or eliminated, then not only building envelopes would be better, but generally they would be more functional and economical and of course the inhabitants will appreciate much better living conditions. This can be the long term vision or priority.

In the meantime it would be fair to aim at some more realistic and moderate targets and promote parallel actions, in order to satisfy the needs that have been characterized as top priorities. Therefore one have to proceed with the following:

1. To amend the insufficient managerial framework,

2. To check the general energy performance of buildings,

3. To enrich the whole aesthetics evaluation system

In order to achieve the above, a lot of partners (statutory bodies like local authorities, governments) and key persons like: tenants, owners and other users, as well as designers, developers, managerial groups, have to be mobilized to highlight the obvious building problems and the respective needs for changes.

\section{References}

[1] Poland, at: www.poland.gov.pl/, www.stat.gov.pl/gus/, ww.stat.gov.pl/gus/5216_PLK_HTML.htm.

[2] www.eurometeo.com/english/climate/city_EPWA/.

[3] Poland \& EU25 Energy, Available: http://www.swivel.com/graphs/show /17040100?graph[scale]=range \& controls=open - .

[4] Energy Yearly Statistics - Polska, Eurostat, 2008,p.303-318, 
Available:http://epp.eurostat.ec.europa.eu/cache/ITY OFFPUB/KS-PC-08-001/EN/KS-PC-08001-EN.PDF.

[5] http://www.mrr.gov.pl/english/Strony/default.aspx.

[6] http://www.rzeszow.pl/.

[7] http://www.smnowemiasto.pl/.

[8] Godfrey, S., Howard, G. (2004). Water Safety Plans (WSP) for Urban Piped Water Supplies in Developing Countries. Loughborough University. 